\title{
Debris Apically Extruded by Two Reciprocating Systems: A Comparative Quantitative Study
}

\author{
Andressa Pinho Amaral ${ }^{1}$ Patrícia Bastos Oliveira Conceição Limongi ${ }^{1}$ Carlos Eduardo Fontana ${ }^{2}$ \\ Alexandre Sigrist De Martin ${ }^{1}$ Carlos Eduardo Da Silveira Bueno ${ }^{1}$ Sérgio Luiz Pinheiro ${ }^{2}$
}

\author{
${ }^{1}$ Endodontics São Leopoldo Mandic, Campinas, São Paulo, Brazil \\ 2Pontifical Catholic University of Campinas (PUC-Campinas), Center \\ for Health Sciences, Postgraduate Program in Health Sciences, \\ Campinas, São Paulo, Brazil
}

\begin{abstract}
Address for correspondence Sérgio Luiz Pinheiro, PhD in Pediatric Dentistry, Pontifical Catholic University of Campinas (PUC-Campinas) Center for Health Sciences, Postgraduate Program in Health Sciences, Campinas, São Paulo 13034-685, Brazil (e-mail: slpinho@puc-campinas.edu.br).
\end{abstract}

\begin{abstract}
Keywords

- apical extrusion

- root canal preparation

- endodontics

Objective The objective of this study was to quantify the amount of debris apically extruded after instrumentation with two reciprocating systems.

Materials and Methods Forty-two single-rooted mandibular premolars with only one straight root canal and apical diameter compatible with a no. $15 \mathrm{~K}$-file were randomly divided into two groups $(n=21)$ according to the instrument used: ProDesign R (Easy Equipamentos; Belo Horizonte, Minas Gerais, Brazil) and Reciproc Blue (VDW; Munich, Germany). Dry Eppendorf tubes were weighed three consecutive times for the initial mean weight. A silicone stopper was then fitted into the mouth of the tube. Each tooth was inserted through the stopper up to the cementoenamel junction and instrumented with one of the two systems to the predetermined working length $(18 \mathrm{~mm})$. The root canals were instrumented per root thirds. At each instrumented root third, the canal was irrigated with $3 \mathrm{~mL}$ of double-distilled water, followed by patency control. Each stopper was then separated from the tube and tubes were incubated at $70^{\circ} \mathrm{C}$ for 5 days. Tubes were again weighed, and the amount of extruded debris was calculated by subtracting the initial mean weight from the final mean weight.

Statistical Analysis Results were analyzed using the Mann-Whitney test at a 5\% significance level.

Results No significant difference was observed in debris extrusion between the ProDesign $\mathrm{R}$ and Reciproc Blue systems ( $p=0.7557)$.

Conclusions The two reciprocating systems tested produced similar amounts of postinstrumentation apically extruded debris.
\end{abstract}

\section{Introduction}

During root canal preparation, a critical step in reducing bacterial load, apical extrusion of pulp tissue remnants, microorganisms, irrigants, and dentin chips into the periradicular tissues may occur, ${ }^{1,2}$ resulting in undesirable consequences such as flare-up, postoperative pain, and delayed periapical healing. ${ }^{3}$ Although authors agree that the extrusion of a certain amount of debris is inevitable, ${ }^{2,4-7}$ smaller amounts have been reported for some systems than for others..$^{8-10}$
Many variables may influence the occurrence of more or less apical extrusion of debris, such as root canal curvature, anatomic variations, patency approach, working length, increased apical preparation size, number of instruments used, and movement kinematics during instrumentation. ${ }^{1,11,12}$ However, with the development of different designs and heat treatments for nickel-titanium alloys and their consequent superelasticity, faster access to the foramen, and possible foraminal enlargement became important factors to be considered in the amount of debris that can be apically extruded. ${ }^{13}$ 
With the introduction of different reciprocating single-file instrumentation systems, it is important to analyze the behavior of these instruments during root canal preparation, and an aspect lacking scientific evidence is the amount of extruded debris. ${ }^{13}$ Therefore, this study aimed to quantify the amount of debris apically extruded after instrumentation with ProDesign R (Easy Equipamentos; Belo Horizonte, Minas Gerais, Brazil) and Reciproc Blue (VDW; Munich, Germany) reciprocating systems. The null hypothesis was that the two systems would not differ in the quantity of apically extruded debris.

\section{Materials and Methods}

The study was approved by the institutional research ethics committee (approval number 2.379.989). Extracted human single-rooted mandibular premolars were selected for the study. All teeth were extracted for therapeutic reasons, and written informed consent was obtained from all patients prior to tooth donation.

Forty-two teeth were used in the study. The sample size was calculated using linear correlation analysis with a correlation coefficient of 0.5848 , number of treatments of two, statistical power of 0.80 , and $\alpha$ of 0.05 .

For inclusion, the teeth were examined visually and radiographically using a digital X-ray sensor (FIT; Micro Imagem, Indaiatuba, São Paulo, Brazil). Only teeth with only one straight root canal and one apical foramen as shown in buccolingual and mesiodistal radiographs, no visible fractures or cracks, no pulp calcifications, no internal or external root resorption, with single fully formed apices with diameter compatible with a no. $15 \mathrm{~K}$-file, and root curvature $<10^{\circ}$, according to Schneider, ${ }^{14}$ were included.

Teeth were stored in 0.9\% saline (ADV Farma; Nova Odessa, São Paulo, Brazil) until use. To remove any periodontal ligament remnants, the surface of the roots was scraped and smoothed with a G1-ultrasonic insert (MMOptics, Jardim São Carlos, São Paulo, Brazil) coupled to an ultrasound system (Emisonic 230; MMOptics).

A no. 1014 round diamond bur (KG Sorensen; Barueri, São Paulo, Brazil) was used to make coronal access cavities, followed by a no. 3082 round diamond bur (KG Sorensen) to remove the roof of the pulp chamber, coupled to a high-speed turbine (EXTRAtorque 505C Turbine; Kavo, Joinville, Santa Catarina, Brazil) under air water spray cooling. The crown cusps were ground with high-speed diamond discs (KG Sorensen) to standardize tooth length at $19 \mathrm{~mm}$. Root length was measured using an analog caliper (Paquímetro Universal 125MEB-6/150; Starrett, Itu, São Paulo, Brazil). Working length was determined $1 \mathrm{~mm}$ short of the measurement made by introducing a no. 10 K-file (Dentsply Maillefer, Ballaigues, Switzerland) into the root canal until its tip became visible at the apical foramen. Apical patency was confirmed using the same file.

We used the experimental model proposed by Myers and Montgomery. ${ }^{15}$ Each dry Eppendorf tube was weighed 3 times on a precision balance (Adventurer Precision; Ohaus Corporation, Parsippany, New Jersey, United States) with an accuracy of $10 \mathrm{~g}$, and the average was calculated and recorded as the initial mean weight. A silicone stopper was then fitted into the mouth of the tube. Each tooth was inserted through the stopper up to the cementoenamel junction, and a $25 \times 0.7 \mathrm{~mm}$ disposable hypodermic needle (PrecisionGlide; BD, Juiz de Fora, Minas Gerais, Brazil) was also inserted into the stopper to equalize the air pressure. Each tube was then held securely in a flask, which was covered with foil to blind the operator for debris extrusion during instrumentation and to avoid manual contact with the tube.

Teeth were randomly divided into two groups $(n=21)$ (www.random.org).

ProDesign R group: A no. 25 ProDesign $\mathrm{R}$ instrument was used in reciprocating motion, coupled to an endodontic motor (VDW Silver; VDW) set to operate in the "Reciproc ALL" mode. After three in-and-out movements (pecks), limited to one-third of the canal or $6 \mathrm{~mm}$, we removed the instrument, cleaned its flutes with gauze, and irrigated the canal with $3 \mathrm{~mL}$ of double-distilled water produced in the laboratory (with needle insertion limited to half of the instrumented root third). Patency was then controlled with a no. $10 \mathrm{~K}$-file, introduced into the root canal until its tip became visible at the apical foramen. We reintroduced the instrument into the canal, limited to three pecks per root third, followed by irrigation and patency control until reaching the predetermined working length.

Reciproc Blue group: A no. 25 Reciproc Blue file was used in a reciprocating motion with in-and-out movements (pecks), coupled to an endodontic motor (VDW Silver; VDW) set to operate in the "Reciproc ALL" mode as previously described for the ProDesign R group.

Each instrument prepared only one root canal. One operator completed all root canal preparations. A total of $9 \mathrm{~mL}$ of double-distilled water was used to irrigate each specimen, dispensed into the canal using a 3-mL syringe with sterile needle (Plastipak; BD), divided into three stages or root thirds $(6 \mathrm{~mm})$. Once instrumentation had been completed, the stopper set-up was separated from the tube. The root was then washed with $1 \mathrm{~mL}$ of double-distilled water to collect the debris adhering to the root surface.

Tubes were incubated at $70^{\circ} \mathrm{C}$ for 5 days to evaporate the double-distilled water. An examiner blinded to group assignment weighed three times the tubes containing extruded debris, and the average was calculated and recorded as the final mean weight. The initial mean weight was subtracted from the final mean weight, and the result was recorded as the amount of extruded debris.

Statistical analysis was performed using BioStat 4.0 (Sociedade Mamirauá, Universidade Federal do Pará, Belém, Brazil). All data were tested for normality using the Shapiro-Wilk test. The sample showed a non-normal distribution, and the results were analyzed using the Mann-Whitney test at a 5\% significance level.

\section{Results}

There was no significant difference between the ProDesign $\mathrm{R}$ and Reciproc Blue groups in postinstrumentation debris extrusion ( $p=0.7557$ ) ( Table 1, - Fig. 1). 
Table 1 Amount of apically extruded debris $(\mathrm{g}$ ) obtained after instrumentation with two reciprocating systems

\begin{tabular}{|l|l|l|l|}
\hline & ProDesign R & Reciproc Blue & $p$-Value \\
\hline Mean (SD) & $0.0011(0.0019)$ & $0.0028(0.0079)$ & 0.7557 \\
& $0.0008(0.0005)$ & $0.0007(0.0007)$ & \\
\hline
\end{tabular}

Abbreviations: IQD, interquartile deviation; SD, standard deviation.

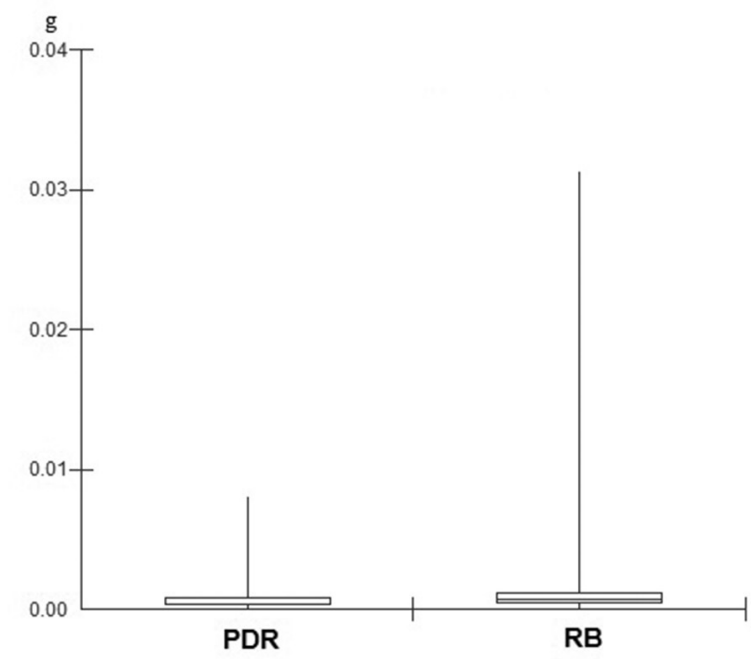

Fig. 1 Box-Plot: apically extruded debris $(\mathrm{g})$ after instrumentation with ProDesign R (PDR) and Reciproc Blue (RB) reciprocating systems.

- Table 1 shows mean (standard deviation) and median (interquartile deviation) values for the amount of apically extruded debris after instrumentation. - Fig. 1 shows the mean and median values in the two groups.

\section{Discussion}

Based on the present results, the null hypothesis was accepted as the ProDesign R and Reciproc Blue systems did not differ in the quantity of postinstrumentation apically extruded debris.

Mandibular premolars with only one straight root canal were used to prevent loss of the working length during root canal preparation, which could result in disruption of the apical constriction and more debris. However, no distinction was made between first and second mandibular premolars to ensure some degree of anatomical variation among specimens, as in previous studies. ${ }^{6,16,17}$

Instruments with a no. 25 apical diameter at D0 were selected from both systems, because this size is closer to the mean anatomical size of the foramen in mandibular premolars, of $\sim 330 \mu \mathrm{m} .{ }^{18}$ The choice of instrument diameter is consistent with a previous study comparing apical debris extrusion with the WaveOne Gold system (Dentsply Tulsa Dental; Tulsa, Oklahoma, United States), the Twisted File Adaptive system (SybronEndo; Orange, California, United States), and manual files, all with a no. 25 apical diameter at $\mathrm{D} 0^{19}$ although in that study the sample consisted of root canals of mandibular molars. In addition to the same tip diameter, the ProDesign $\mathrm{R}$ and Reciproc Blue instruments share the same S-shaped cross-section. This design feature increases the cutting efficiency of the instrument but also reduces the core volume along its active part, which may increase dentin chip collection during preparation and the flexibility of intermediate portions, ${ }^{20}$ thus reducing the amount of debris that can be apically extruded.

This study used double-distilled water as an irrigant, in agreement with previous studies, ${ }^{8,19}$ because sodium hypochlorite undergoes crystallization during evaporation in the incubator, contributing to an increase in the weight of debris because of the sodium crystals become attached to the debris. The apically extruded debris was quantitatively evaluated using a previously described method. ${ }^{15}$ Despite the shortcoming of failing to reproduce resistance of periapical tissues, this method is widely accepted and allows the comparison of systems in the laboratory setting. ${ }^{8,17,19}$ There are other techniques that use foam to simulate periapical resistance. ${ }^{21,22}$ However, this set-up also has shortcomings such as irrigant and debris absorption, which, in a quantitative study, may interfere with the results.

Our results indicate that apical extrusion of debris occurs regardless of the type of reciprocating instrument used, in agreement with previous studies, ${ }^{1,6,9,11}$ since, during root canal instrumentation, the walls reached by the irrigant are cut by the instruments, thereby producing debris. Although the design of these instruments (smaller core, high superelasticity, and deep helical channels) contribute positively to reduce this effect, some degree of extrusion is inevitable.

Frota et $\mathrm{al}^{13}$ tested reciprocating instruments made of thermally treated alloys (Reciproc, WaveOne, and ProDesign $\mathrm{R}$ ) and concluded that significantly less apical debris was extruded by ProDesign R than by the other systems, in contrast to the results of the present study, in which no significant difference was observed between the systems. However, in the present study, a high standard deviation was observed in the Reciproc Blue group, which may be explained by the greater taper and its variation along the active part of the instrument, leading to heterogenous dentin removal with substantial variation in extruded debris between the samples in this experimental group.

Another point that needs to be emphasized is that the heat treatment to which the files tested in the present study were subjected probably did not influence the results, since the sample consisted of mandibular premolars with root curvature $<10^{\circ}$. Frota et $\mathrm{al}^{13}$ used a sample of mesial root canals of mandibular molars with foramen diameters lower than $200 \mu \mathrm{m}$ and working lengths different from that used in the 
present study. Another possible explanation for this difference is the different standardization process of the foramina, which, despite using the same reference instrument (no. 15 file), is not as accurate as microscopic and/or digital analyses. In addition, the cross-sections of the test systems selected by Frota et $\mathrm{al}^{13}$ differed from each other, leading to changes in flexibility, cutting efficiency, and consequently in debris extrusion.

Uslu et $\mathrm{al}^{23}$ tested the Reciproc Blue, HyFlex EDM (Coltene) Whaledent, Altstätten, Switzerland), and XP-endo Shaper (FKG Dentaire SA, La Chaux-de-Fonds, Switzerland) systems and concluded that Reciproc Blue extruded more debris than the other systems. Although their sample was similar to ours, they used a modification of the method proposed by Lu et $\mathrm{al}^{22}$ by using Teflon bands on the surface of the roots and injecting agar gel into Eppendorf tubes.

A single operator, experienced in the systems tested in the present study, completed all root canal preparations. This may have contributed to the similar results in terms of debris extrusion obtained with the Reciproc Blue and Prodesig R systems, regardless of differences in taper and heat treatment between the instruments.

Within the limitations of an in vitro study, it can be concluded that the two test reciprocating systems produced similar amounts of apically extruded debris. Further studies are required to confirm these results.

\section{Conflict of Interest}

None declared.

\section{References}

1 Bürklein S, Schäfer E. Apically extruded debris with reciprocating single-file and full-sequence rotary instrumentation systems. J Endod 2012;38(6):850-852

2 Mendonça de Moura JD, Bueno CEDS, Fontana CE, Pelegrine RA. Extrusion of debris from curved root canals instrumented up to different working lengths using different reciprocating systems. J Endod 2019;45(7):930-934

3 Ozsu D, Karatas E, Arslan H, Topcu MC. Quantitative evaluation of apically extruded debris during root canal instrumentation with ProTaper Universal, ProTaper Next, WaveOne, and self-adjusting file systems. Eur J Dent 2014;8(4):504-508

4 Tanalp J, Güngör T. Apical extrusion of debris: a literature review of an inherent occurrence during root canal treatment. Int Endod J 2014;47(3):211-221

5 Üstün Y, Çanakçi BC, Dinçer AN, Er O, Düzgün S. Evaluation of apically extruded debris associated with several Ni-Ti systems. Int Endod J 2015;48(7):701-704

6 Topçuoğlu HS, Zan R, Akpek F, et al. Apically extruded debris during root canal preparation using Vortex Blue, K3XF, ProTaper Next and Reciproc instruments. Int Endod J 2016;49(12):1183-1187

7 Uzunoglu E, Turker SA. Impact of different file systems on the amount of apically extruded debris during endodontic retreatment. Eur J Dent 2016;10(2):210-214
8 Bürklein S, Benten S, Schäfer E. Quantitative evaluation of apically extruded debris with different single-file systems: Reciproc, F360 and OneShape versus Mtwo. Int Endod J 2014;47(5):405-409

9 Kirchhoff AL, Fariniuk LF, Mello I. Apical extrusion of debris in flat-oval root canals after using different instrumentation systems. J Endod 2015;41(2):237-241

10 Yılmaz K, Özyürek T. Apically extruded debris after retreatment procedure with reciproc, ProTaper next, and twisted file adaptive instruments. J Endod 2017;43(4):648-651

11 De-Deus G, Neves A, Silva EJ, et al. Apically extruded dentin debris by reciprocating single-file and multi-file rotary system. Clin Oral Investig 2015;19(2):357-361

12 Silva EJ, Teixeira JM, Kudsi N, Sassone LM, Krebs RL, Coutinho-Filho TS. Influence of apical preparation size and working length on debris extrusion. Braz Dent J 2016;27(1):28-31

13 Frota MMA, Bernardes RA, Vivan RR, Vivacqua-Gomes N, Duarte MAH, Vasconcelos BC. Debris extrusion and foraminal deformation produced by reciprocating instruments made of thermally treated NiTi wires. J Appl Oral Sci 2018;26:e20170215

14 Schneider SW. A comparison of canal preparations in straight and curved root canals. Oral Surg Oral Med Oral Pathol 1971;32(2):271-275

15 Myers GL, Montgomery S. A comparison of weights of debris extruded apically by conventional filing and Canal Master techniques. J Endod 1991;17(6):275-279

16 Koçak S, Koçak MM, Sağlam BC, Türker SA, Sağsen B, Er Ö. Apical extrusion of debris using self-adjusting file, reciprocating single-file, and 2 rotary instrumentation systems. J Endod 2013;39(10):1278-1280

17 Koçak MM, Çiçek E, Koçak S, Sağlam BC, Yılmaz N. Apical extrusion of debris using ProTaper Universal and ProTaper Next rotary systems. Int Endod J 2015;48(3):283-286

18 Bürgel MO, Borba de MG. SEM analysis of apical anatomy of mandibular premolars. RFO UPF 2011;16(1):49-53

19 Boijink D, Costa DD, Hoppe CB, Kopper PMP, Grecca FS. Apically extruded debris in curved root canals using the WaveOne Gold reciprocating and Twisted File Adaptive systems. J Endod 2018;44(8):1289-1292

20 Rodrigues RCV, Zandi H, Kristoffersen AK, et al. Influence the apical preparation size and the irrigant type on bacterial reduction in root canal-treated teeth with apical periodontitis. J Endod 2017;43(7):1058-1063

21 Altundasar E, Nagas E, Uyanik O, Serper A. Debris and irrigant extrusion potential of 2 rotary systems and irrigation needles. Oral Surg Oral Med Oral Pathol Oral Radiol Endod 2011;112(4):e31-e35

22 Lu Y, Wang R, Zhang L, et al. Apically extruded debris and irrigant with two Ni-Ti systems and hand files when removing root fillings: a laboratory study. Int Endod J 2013;46(12):1125-1130

23 Uslu G, Özyürek T, Yılmaz K, Gündoğar M, Plotino G. Apically extruded debris during root canal instrumentation with Reciproc Blue, HyFlex EDM and XP-endo Shaper nickel-titanium files. J Endod 2018;44(5):856-859 